\title{
Macropore Formation and Pore Morphology Characterization of Heavily Doped p-Type Porous Silicon
}

\author{
David Martín-Sánchez, 1 Salvador Ponce-Alcántara, Paula Martínez-Pérez, \\ and Jaime García-Rupérez ${ }^{\mathrm{Z}}$
}

Nanophotonics Technology Center (NTC), Universitat Politècnica de València, 46022 Valencia, Spain

\begin{abstract}
Tuning the pore diameter of porous silicon films is essential for some applications such as biosensing, where the pore size can be used for filtering analytes or to control the biofunctionalization of its walls. However, macropore ( $>50 \mathrm{~nm})$ formation on p-type silicon is not yet fully controlled due to its strong dependence on resistivity. Electrochemical etching of heavily doped p-type silicon usually forms micropores $(<5 \mathrm{~nm})$, but it has been found that bigger sizes can be achieved by adding an organic solvent to the electrolyte. In this work, we compare the results obtained when adding dimethylformamide (DMF) and dimethylsulfoxide (DMSO) to the electrolyte as well as the effect of a post-treatment of the sample with potasium hydroxide $(\mathrm{KOH})$ and sodium hydroxide $(\mathrm{NaOH})$ for macropore formation in p-type silicon with resistivities between 0.001 and $10 \Omega \cdot \mathrm{cm}$, achieving pore sizes from 5 to $100 \mathrm{~nm}$.

(C) The Author(s) 2019. Published by ECS. This is an open access article distributed under the terms of the Creative Commons Attribution 4.0 License (CC BY, http://creativecommons.org/licenses/by/4.0/), which permits unrestricted reuse of the work in any medium, provided the original work is properly cited. [DOI: 10.1149/2.0051902jes]

(cc) BY
\end{abstract}

Manuscript submitted September 26, 2018; revised manuscript received December 21, 2018. Published January 3, 2019.

Porous silicon (PS) is a nanostructured material with many application areas such as optoelectronics, biomedicine or energy conversion. In optoelectronics, it is particularly useful mainly because it retains the advantages of Si technology while adding the ability of controlling the optical properties. PS has received even more interest since the demonstration that it could emit visible photoluminescence. ${ }^{1}$ Additionally, the ability of modifying the refractive index of the PS film as well as the possibility of fabricating layered structures have allowed the development of multiple optical interference devices operating in a wide range of the electromagnetic spectrum. ${ }^{2}$

Another highly promising research field concerning porous silicon is biomedical applications. The controllable geometry, the extremely high specific surface area available and its biocompatibility and biodegradability make PS suitable for drug delivery, cancer immunotherapy, gas sensing or biodetection. ${ }^{3-6}$ It can be also easily functionalized with a wide repertoire of surface chemistries which, for instance, allows chemically attaching receptors of different analytes, e.g. proteins, antibodies and enzymes, to the internal surface of the pores. ${ }^{7-9}$ Tuning the PS properties can help achieve high sensitivity sensors or controlled release behavior when used as a drug carrier.

Within the energy conversion domain, PS has also attracted attention because of its use as a potential anode material for $\mathrm{Li}$-ion batteries. ${ }^{10}$ The performance of $\mathrm{Si}$ anodes is limited by its large volume expansion during charge/discharge cycles. Introducing voids, however, allows to accommodate this expansion and shrinkage of the material, improving the capacity retention. The main efforts have been directed toward developing hollow core-shell and yolk-shell structures, ${ }^{11-13}$ but PS can enhance the anode performance in a similar way. ${ }^{14,15}$ Optimizing the amount of voids in the PS film can lead to little or no change of the total volume during cycling and prevent cracking of the structure.

PS is generated by electrochemically etching silicon ( $\mathrm{Si}$ ) in electrolytes containing hydrofluoric acid (HF). ${ }^{6}$ The growth of the pores consists in a combination of two chemical reactions: the direct dissolution of $\mathrm{Si}$ in fluoride and the oxidation of $\mathrm{Si}$ in the presence of oxygen and its later dissolution. ${ }^{16}$ Both reactions are strongly dependent on the etching conditions, both chemical and electrical. ${ }^{17}$ Porosity, thickness, pore diameter, pore morphology and distance between pores are some of the properties that can be tuned during fabrication. ${ }^{18}$ Unfortunately, not all combinations of the parameters are possible or at least different approximations must be carried out to overcome the initial limitations.

The macropore (pores with an average diameter greater than $50 \mathrm{~nm}$ ) formation mechanism on n-type $\mathrm{Si}$ is well known. ${ }^{17,19}$

${ }^{\mathrm{z}}$ E-mail: jaigarru@ntc.upv.es
Low-doped p-type Si wafers have also been used for the formation of macropores. ${ }^{20}$ However, achieving mesopores (5-50nm) and macropores in moderately-doped and heavily-doped $\mathrm{Si}$ is more challenging. Aqueous HF-based electrolytes (HF diluted in water and optionally surfactants such as alcohols) will yield only micropores $(<5 \mathrm{~nm})$ and mesopores if no additional fabrication steps are introduced..$^{21,22}$ In order to overcome this limitation, several approaches have been developed.

Post-fabrication pore size expansion is one way of achieving mesopores. Thermally oxidizing PS film grows a layer of silicon oxide $\left(\mathrm{SiO}_{2}\right)$ of a few nanometers over and into the pore walls. Dipping the sample in $\mathrm{HF}$ afterwards will remove the created $\mathrm{SiO}_{2}$ layer, thus increasing the pore diameter up to half the grown layer thickness. ${ }^{23}$ This process can be repeated, yet doing so will reduce the pore wall thickness and jeopardize the structure stability. Alkaline mixtures such as $\mathrm{KOH}$ and $\mathrm{NaOH}$ solutions anisotropically etch $\mathrm{Si}$ and can also be used to expand the pores after fabrication, ${ }^{24}$ although this method has the same limitations as the previous one.

Alternatively, using organic electrolytes instead of aqueous ones is a good approach for obtaining meso- and macropore PS films. The combination of HF-based solutions with some surfactants, e.g., dimethylformamide and dimethylsulfoxide, facilitates the Si dissolution during anodization. ${ }^{25,26}$ This method offers more control of PS properties.

Even though numerous studies have reported the formation of macropores on heavily-doped p-type $\mathrm{Si}$, there is a lack of analysis for certain ranges of resistivities. In this work, we compare some of these approaches in p-type silicon with resistivities between 0.001 and $10 \Omega \cdot \mathrm{cm}$

\section{Experimental}

PS was prepared by electrochemically etching p-type Si wafers (boron doped, $<100>$ oriented) with different resistivities: $0.001-0.005 \Omega \cdot \mathrm{cm}, 0.01-0.02 \Omega \cdot \mathrm{cm}$ and $9-10 \Omega \cdot \mathrm{cm}$, all three purchased from MicroChemicals $\mathrm{GmbH}$ (Germany). Aqueous electrolytes were prepared with Ethanol (EtOH) supplied by Scharlab S.L. (Spain) and hydrofluoric acid (HF) (48\% solution in water) purchased from BASF (Germany). For organic electrolytes, N,N-Dimethylformamide (DMF) from Sigma-Aldrich (USA) and Dimethylsulfoxide (DMSO) from Scharlab S.L. (Spain) were employed. In the cases in which alkaline solutions were used, potassium hydroxide $(\mathrm{KOH})$, obtained from Panreac S.L. (Spain), and sodium hydroxide $(\mathrm{NaOH})$, from Scharlab S.L. (Spain), were mixed in different concentrations with deionized water (DIW) produced in house with a Millipore water purification system. 
Table I. Influence of resistivity on pore morphology.

\begin{tabular}{llll} 
Resistivity of wafer & $0.001-0.005 \Omega \cdot \mathrm{cm}$ & $0.01-0.02 \Omega \cdot \mathrm{cm}$ & $9-10 \Omega \cdot \mathrm{cm}$ \\
\hline HF concentration & $37.5 \%$ & $37.5 \%$ & $33 \%$ \\
Resistivity of the electrolyte & $10 \Omega \cdot \mathrm{cm}$ & $20 \Omega \cdot \mathrm{cm}$ & $50 \Omega \cdot \mathrm{cm}$ \\
Current range for PS formation & $<750 \mathrm{~mA} / \mathrm{cm}^{2}$ & $<300 \mathrm{~mA} / \mathrm{cm}^{2}$ & $<150 \mathrm{~mA} / \mathrm{cm}^{2}$ \\
Pore shape - surface & Holes & Holes & Holes \\
Pore shape - section & Secondary branches only & Secondary branches only & Secondary branches only \\
Pore diameter & $<10 \mathrm{~nm}$ & $<10 \mathrm{~nm}$ & $<10 \mathrm{~nm}$ \\
Etch rate & $\sim 250 \mathrm{~nm} / \mathrm{s}, \mathrm{I}=400 \mathrm{~mA} / \mathrm{cm}^{2}, \mathrm{~T}=30 \mathrm{~s}$ & $\sim 80 \mathrm{~nm} / \mathrm{s}, \mathrm{I}=150 \mathrm{~mA} / \mathrm{cm}^{2}, \mathrm{~T}=310 \mathrm{~s}$ & $\sim 40 \mathrm{~nm} / \mathrm{s}, \mathrm{I}=70 \mathrm{~mA} / \mathrm{cm}^{2}, \mathrm{~T}=310 \mathrm{~s}$ \\
Spacing between pores & $\sim 20 \mathrm{~nm}$ & $\sim 30 \mathrm{~nm}$ & $\sim 40 \mathrm{~nm}$
\end{tabular}

For cleaning purposes, all samples were pretreated for 30min in a 3:1 volumetric mixture of sulfuric acid $\left(\mathrm{H}_{2} \mathrm{SO}_{4}\right)$ and hydrogen Peroxide $\left(\mathrm{H}_{2} \mathrm{O}_{2}\right)$, both purchased from BASF (Germany), for removing organic residues off the substrate. Afterward, they were dipped into a solution of $<5 \% \mathrm{HF}$ for 30 s in order to eliminate the native oxide layer.

Electrochemical etching of $\mathrm{Si}$ was performed under galvanostatic conditions using a custom-made vertical cell in which a Pt electrode worked as cathode and the Si itself as anode. Different aqueous and organic solutions were used as electrolytes. An Agilent E3648A current generator was used, remotely controlled by a LabVIEW-based program.

After anodization, some samples were partially oxidized in an additional step with the aim of increasing pore size. A PVA Tepla 200 (PVA Tepla, Germany) microwave plasma was used during 20min (1.5mbar, $\mathrm{O}_{2}$ flow, $400 \mathrm{~W}$ ) in order to grow a thin layer of $\mathrm{SiO}_{2}$.

All PS films were characterized after fabrication. Field emission scanning electron microscopy (FESEM) images were obtained using both a Hitachi S-4500 SEM and a Zeiss Ultra 55 microscope. The average pore diameter and pore interspacing were statistically determined with ImageJ processing software ${ }^{27}$ Reflectance spectra were measured with a Fourier-Transform Infrared Spectroscopy (FTIR) system (Bruker, USA) in the range between 650 and 900nm. Attenuated Total Reflection (ATR) FTIR spectra were also obtained with the former equipment in the range between 600 and $3500 \mathrm{~cm}^{-1}$.

\section{Results}

The results of the pore morphology dependence with p-type Si wafer resistivity using only aqueous electrolytes and no additional treatment are summarized in Table I. In Table II the effects of using an organic electrolyte are shown for the case of p-type Si wafers with resistivities of $0.01-0.02 \Omega \cdot \mathrm{cm}$. Organic electrolytes show equivalent effects in the rest of p-type Si wafers used for this work, following similar trends to the ones presented in Table I. At last, in Table III we present the result of applying additional steps after fabrication for increasing the pore diameter.

In this work we only present results of PS samples fabricated in the safe range of the parameters, meaning that all samples are structurally stable. PS films can be obtained beyond that range, up to the electropolishing current, but these layers might collapse due to their extremely high porosities and are therefore omitted here.

\section{Discussion}

Using organic electrolytes in p-type $\mathrm{Si}$ with resistivities of $0.01-0.02 \Omega \cdot \mathrm{cm}$ offers a wider range of possibilities when designing PS layers with different pore diameters and/or morphologies. Pore sizes can be tuned from the micropore to near the macropore region and their cross-sectional shape can present secondary branches, when using DMF, or smooth walls, in the case of DMSO (Figure 1). The distance between pores can also be controlled, being smaller when using DMSO instead of DMF. However, extremely narrow spacing might compromise the structural stability.

The higher the resistivity, the lower the pore density, ${ }^{26}$ and for this reason pores tend to be bigger in lowly-doped p-type Si. In our case, for p-type Si wafers with resistivities of $9-10 \Omega \cdot \mathrm{cm}$ we expect to achieve PS films in the macropore region, such as in Ref. 25. Unfortunately, galvanostatic conditions for electrochemically etching those samples are beyond the performance of the equipment used in this work and can therefore not be experimentally proven.

No macropore PS film was achieved for any combination of the etching parameters when using aqueous electrolytes. Pore diameter can be increased reducing HF concentration but this implies thin walls and a slow vertical growth, leading to sponge-like layers. PS films created this way are structurally weak and only a small range of porosities can be achieved.

$\mathrm{SiO}_{2}$ removal increases pore size but in a small percentage. FTIR reflectance measurements demonstrate this effect (Figure 2). The spectrum of the oxidized PS layer shifts toward shorter wavelengths with respect to the non-oxidized PS due to the substitution of part of the $\mathrm{Si}$ by $\mathrm{SiO}_{2}$, which has a lower refractive index. When the oxide layer is removed by dipping the sample in $\mathrm{HF}$, the spectrum once again shifts toward shorter wavelengths as a result of the dissolution of the $\mathrm{SiO}_{2}$, thus increasing the porosity. ATR-FTIR measurements have also been carried out to characterize changes in the composition. Most PS films display an absorbance profile similar to the one in Figure $3 \mathrm{a}^{28}$ Stretching modes of $\mathrm{SiH}_{\mathrm{x}}(\mathrm{x}=1,2,3)$ have overlapping peaks at 2115,2090 and $2141 \mathrm{~cm}^{-1}$, respectively. $\mathrm{SiH}_{2}$ scissor mode can be seen at $915 \mathrm{~cm}^{-1}$ and the deformation modes of $\mathrm{SiH}_{\mathrm{x}}$ at 615,622 and $666 \mathrm{~cm}^{-1}$, overlapping Si-Si absorbance peak of crystalline Si. Additionally, the bulk Si-O-Si mode can be seen at $1108 \mathrm{~cm}^{-1}$. The first

Table II. Influence of organic electrolytes on pore morphology for resistivities of $0.01-0.02 \Omega \cdot \mathrm{cm}$.

Surfactant

HF concentration

Resistivity of the electrolyte

Current range for PS formation

Pore shape - surface

Pore shape - section

Pore diameter

Etch rate

Spacing between pores
DMF

$8 \%$
$500 \Omega \cdot \mathrm{cm}$
$<25 \mathrm{~mA} / \mathrm{cm}^{2}$
Holes
Secondary branches only
$\sim 25 \mathrm{~nm}$
$\sim 20 \mathrm{~nm} / \mathrm{s}, \mathrm{I}=22 \mathrm{~mA} / \mathrm{cm}^{2}, \mathrm{~T}=90 \mathrm{~s}$
$\sim 40 \mathrm{~nm}$


Table III. Influence on pore morphology of different treatments performed after fabrication.

\begin{tabular}{llll} 
Post-treatment & $\mathrm{NaOH}$ & Oxidation & $\mathrm{KOH}$ \\
\hline Resistivity of wafer & $0.001-0.005 \Omega \cdot \mathrm{cm}$ & $0.01-0.02 \Omega \cdot \mathrm{cm}$ & $0.01-0.02 \Omega \cdot \mathrm{cm}$ \\
HF concentration & $37.5 \%$ & $17 \%$ & $17 \%$ \\
Resistivity of the electrolyte & $10 \Omega \cdot \mathrm{cm}$ & $100 \Omega \cdot \mathrm{cm}$ & $100 \Omega \cdot \mathrm{cm}$ \\
Current range for PS formation & $<750 \mathrm{~mA} / \mathrm{cm}^{2}$ & $<130 \mathrm{~mA} / \mathrm{cm}^{2}$ & $<130 \mathrm{~mA} / \mathrm{cm}^{2}$ \\
Pore shape - surface & Holes & Holes & Holes \\
Pore shape - section & Secondary branches only & Secondary branches only & Secondary branches only \\
Pore diameter & $\sim 100 \mathrm{~nm}$ & $\sim 25 \mathrm{~nm}$ & $\sim 25 \mathrm{~nm}$ \\
Etch rate & $\sim 450 \mathrm{~nm} / \mathrm{s}, \mathrm{I}=730 \mathrm{~mA} / \mathrm{cm}^{2}, \mathrm{~T}=30 \mathrm{~s}$ & $\sim 8 \mathrm{~nm} / \mathrm{s}, \mathrm{I}=6 \mathrm{~mA} / \mathrm{cm}^{2}, \mathrm{~T}=100 \mathrm{~s}$ & $\sim 8 \mathrm{~nm} / \mathrm{s}, \mathrm{I}=6 \mathrm{~mA} / \mathrm{cm}^{2}, \mathrm{~T}=120 \mathrm{~s}$ \\
Spacing between pores & $\sim 20 \mathrm{~nm}$ & $\sim 30 \mathrm{~nm}$ & $\sim 60 \mathrm{~nm}$
\end{tabular}
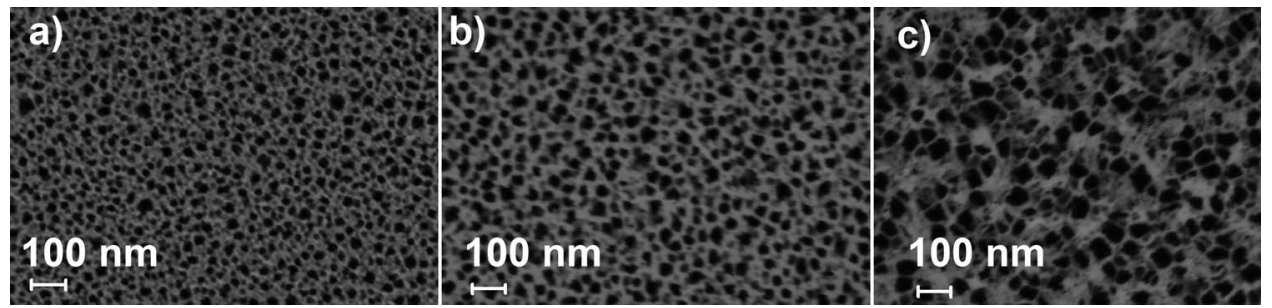

Figure 1. FESEM images of electrochemically etched p-type Si 0.01-0.02 $2 \cdot \mathrm{cm}$. (a) HF:DIW:DMF 1:1:4, I = 22mA/ $\mathrm{cm}^{2}$, T = 90s; (b) HF:DIW:DMF 1:1:9, $\mathrm{I}=11 \mathrm{~mA} / \mathrm{cm}^{2}, \mathrm{~T}=90 \mathrm{~s}$ and (c) HF:DIW:DMSO 1:1:9, I $=11 \mathrm{~mA} / \mathrm{cm}^{2}, \mathrm{~T}=90 \mathrm{~s}$.

evidence of partially oxidized PS (Figure 3b) is the intensity decrease of $\mathrm{SiH}_{\mathrm{x}}$ stretching modes and their shift to 2160,2199 and $2254 \mathrm{~cm}^{-1}$. A broad band near the existing Si-O-Si mode grows with a maximum at $1050 \mathrm{~cm}^{-1}$. Furthermore, $\mathrm{SiH}_{2}$ scissor and $\mathrm{SiH}_{\mathrm{x}}$ deformation modes are partially diminished.

Alkaline etching of the samples also increases slightly the pore size. Both $\mathrm{SiO}_{2}$ removal and alkaline etching yield similar results except for the distance between pores, which increases in the case of the PS films etched with a KOH solution (Figure 4). This effect is caused by the deposition of the dissolved $\mathrm{Si}$ on the surface, obstructing some pores, and could be reduced if agitation is added. As depicted in the FTIR reflectance measurements (Figure 5), the shift of the spectrum is comparable to that observed for the oxidized PS. This provides an approximation of the porosity increase achieved with this method.

As for heavily doped p-type $\mathrm{Si}$ wafers with resistivities such as $0.001-0.005 \Omega \cdot \mathrm{cm}$, a high $\mathrm{HF}$ concentration causes a fast dissolution of the $\mathrm{Si}$, since the fluoride $\left(\mathrm{F}^{-}\right)$quickly finds a free charge $\left(\mathrm{h}^{+}\right)$that

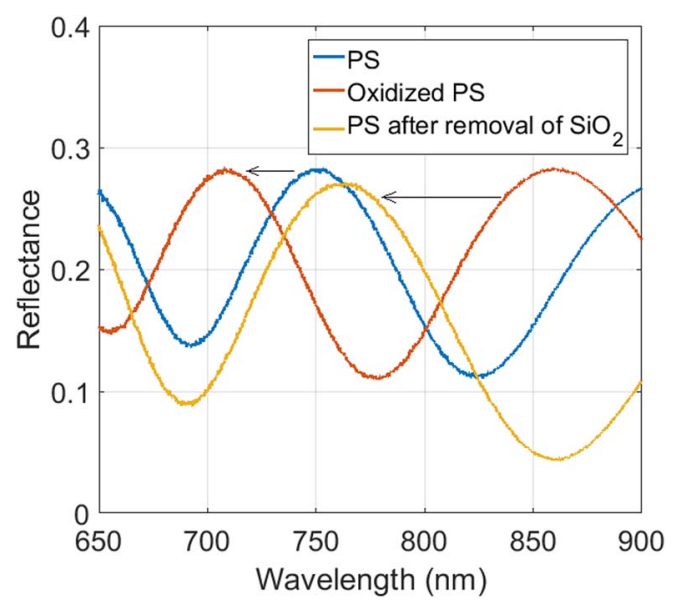

Figure 2. FTIR reflectance spectra of electrochemically etched p-type $\mathrm{Si}$ $0.01-0.02 \Omega \cdot \mathrm{cm}, \mathrm{HF}:$ EtOH $1: 2, \mathrm{I}=6 \mathrm{~mA} / \mathrm{cm}^{2}, \mathrm{~T}=100 \mathrm{~s}$ (blue line); after being oxidized for $20 \mathrm{~min}$ (red line) and after being dipped in HF for removing $\mathrm{SiO}_{2}$ layer (yellow line). triggers the reaction. This causes the formation of micropores with a high pore density. However, this fast etch rate soon leads to a poor $\mathrm{F}^{-}$ replacement at the pore tip, which causes an increase of the pore diameter. As a result, a PS film with a bad vertical uniformity is achieved,

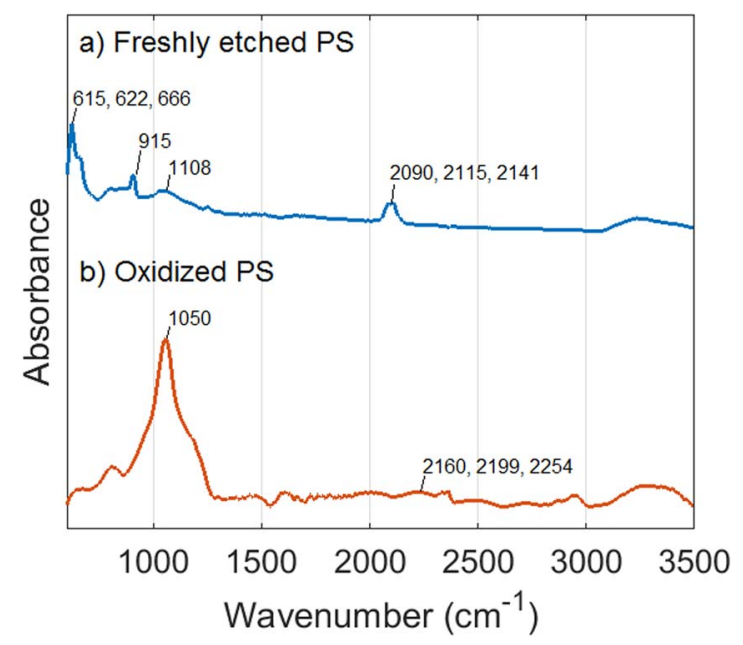

Figure 3. ATR-FTIR absorbance spectra of electrochemically etched p-type Si $0.01-0.02 \Omega \cdot \mathrm{cm}, \mathrm{HF}:$ EtOH 1:2, I $=6 \mathrm{~mA} / \mathrm{cm}^{2}, \mathrm{~T}=100 \mathrm{~s}$, (a) freshly etched and (b) oxidized for $20 \mathrm{~min}$.
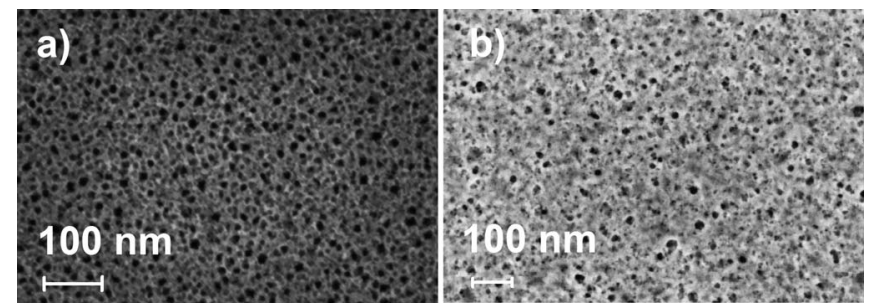

Figure 4. FESEM images of electrochemically etched p-type $\mathrm{Si} 0.01$ $0.02 \Omega \cdot \mathrm{cm}$. (a) HF:EtOH $1: 2, \mathrm{I}=6 \mathrm{~mA} / \mathrm{cm}^{2}, \mathrm{~T}=100 \mathrm{~s}$, oxidized for $20 \mathrm{~min}$ and dipped in HF and (b) HF:EtOH 1:2, I $=6 \mathrm{~mA} / \mathrm{cm}^{2}, \mathrm{~T}=120 \mathrm{~s}$, etched with $45 \mathrm{mg}$ of $\mathrm{KOH}$ in $100 \mathrm{ml}$ of DIW for $5 \mathrm{~min}$. 


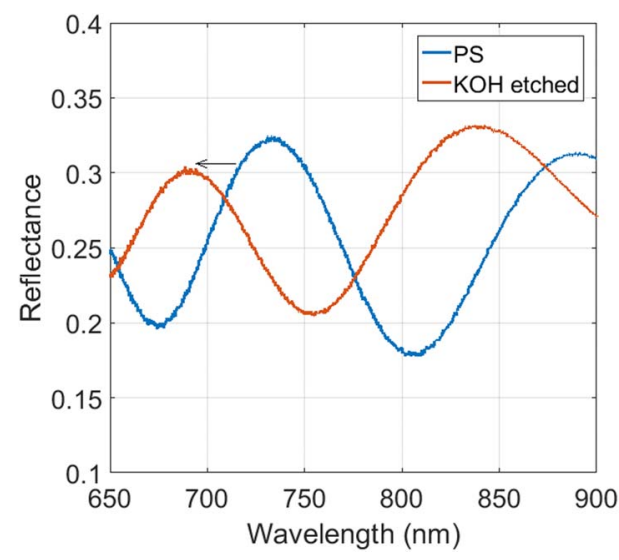

Figure 5. FTIR reflectance spectra of electrochemically etched p-type $\mathrm{Si}$ $0.01-0.02 \Omega \cdot \mathrm{cm} \mathrm{HF}:$ EtOH 1:2, $\mathrm{I}=6 \mathrm{~mA} / \mathrm{cm}^{2}, \mathrm{~T}=100 \mathrm{~s}$ (blue line) and after etching with $45 \mathrm{mg}$ of $\mathrm{KOH}$ in $100 \mathrm{ml}$ of DIW for $5 \mathrm{~min}$ (red line).

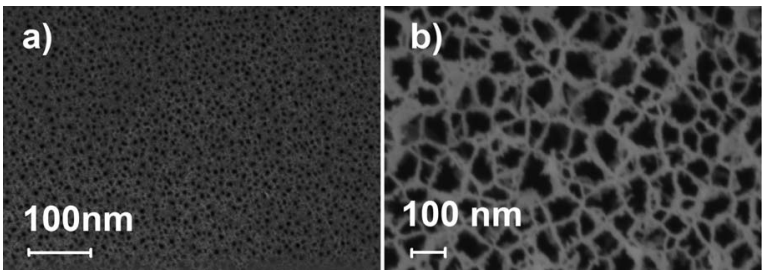

Figure 6. FESEM images of electrochemically etched p-type $\mathrm{Si} 0.001-$ $0.005 \Omega \cdot \mathrm{cm}$. (a) HF:EtOH $2: 1, \mathrm{I}=650 \mathrm{~mA} / \mathrm{cm}^{2}, \mathrm{~T}=30 \mathrm{~s}$ and (b) HF:EtOH $2: 1, \mathrm{I}=730 \mathrm{~mA} / \mathrm{cm}^{2}, \mathrm{~T}=30 \mathrm{~s}$, dissolved $2 \mathrm{~min}$ in $0.1 \mathrm{M} \mathrm{NaOH}$. Notice that the pores in (a) are hardly visible given its small size, which is close to the resolution of the microscope.

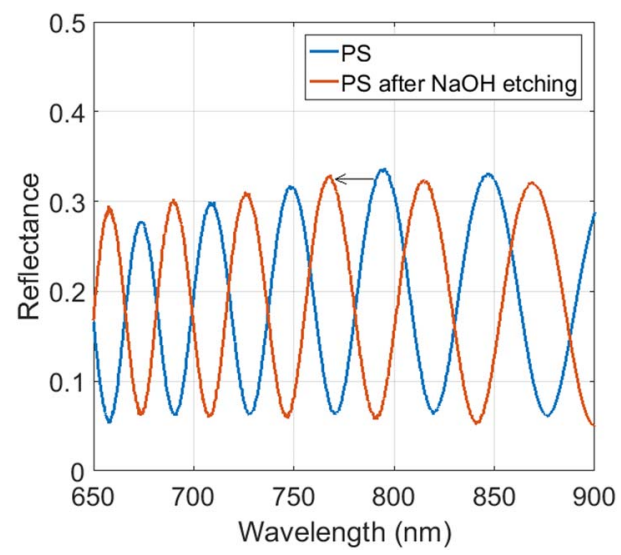

Figure 7. FTIR reflectance spectra of electrochemically etched p-type Si $0.001-0.005 \Omega \cdot \mathrm{cm} \mathrm{HF}:$ EtOH $2: 1, \mathrm{I}=200 \mathrm{~mA} / \mathrm{cm}^{2}, \mathrm{~T}=30 \mathrm{~s}$ (blue line) and after dissolution with $0.1 \mathrm{M} \mathrm{NaOH}$ for 30 s (red line).

with pores increasing their size $\mathrm{x} 10$ along the thickness of the layer. We can take advantage of that effect for obtaining macropores by removing the top section of the layer. An easy way of doing this is etching with $1 \mathrm{M} \mathrm{NaOH}$ for a few seconds (see Figure 6). Figure 7 shows the reflectance spectrum shift as a result of the porosity increase after the removal of the microporous layer on top.

\section{Conclusions}

Pore morphology and fabrication properties for PS formed in heavily doped p-type $\mathrm{Si}$ (100) have been presented. The effect of organic electrolytes such as DMF and DMSO and alkaline etchants e.g. $\mathrm{KOH}$ and $\mathrm{NaOH}$ has been reported. The use of organic electrolytes on $\mathrm{Si}$ wafers with resistivities of $0.01-0.02 \Omega \cdot \mathrm{cm}$ has proven the increase of the average pore diameter to up to $40 \mathrm{~nm}$. On the other hand, pore sizes of around $100 \mathrm{~nm}$ can be achieved on wafers with resisitivities of $0.001-0.005 \Omega \cdot \mathrm{cm}$.

\section{Acknowledgments}

The authors acknowledge the funding from the Spanish government through the project TEC2015-63838-C3-1-ROPTONANOSENS.

\section{ORCID}

David Martín-Sánchez (D https://orcid.org/0000-0003-0131-5226

\section{References}

1. L. T. Canham, Appl. Phys. Lett., 57, 10 (1990).

2. V. Torres-Costa and R. J. Martín-Palma, J. Mater. Sci., 45 (2010)

3. W. Li, Z. Liu, F. Fontana, Y. Ding, D. Liu, J. T. Hirvonen, and H. A. Santos, $A d v$. Mater, 30, 1703740 (2018).

4. C. Baker and J. L. Gole, JSM Nanotechnol. Nanomed., 2(1), 1021 (2014).

5. S. Dhanekar and S. Jain, Biosens. Bioelectron., 41 (2013).

6. C. Pacholski, Sensors, 13, 4697 (2013).

7. T. Hutter, M. Horesh, and S. Ruschin, Sens. Actuators B, 152, 29 (2011).

8. S. Mariani, L. M. Strambini, and G. Barillaro, Anal. Chem., 88, 8502 (2016).

9. R. Caroselli, S. Ponce-Alcántara, F. Prats-Quílez, D. Martín-Sánchez, L. Torrijos-Morán, A. Griol-Barres, L. Bellieres, H. Bandarenka, K. Girel, V. Bondarenko, and J. García-Rupérez, Opt. Express, 25, 31651 (2017).

10. M. Ashuri, Q. He, and L. L. Shaw, Nanoscale, 8, 74 (2016).

11. M. Ashuri, Q. He, Y. Liu, K. Zhang, S. Emani, M. S. Sawicki, J. S. Shamie, and L. L. Shaw, Electrochim. Acta, 2016, 215, 126 (2016).

12. M. Ashuri, Q. He, Y. Liu, S. Emani, and L. L. Shaw, Electrochim. Acta, 2017, 258, 274 (2017).

13. M. Ashuri, Q. He, K. Zhang, S. Emani, and L. L. Shaw, J. Sol-Gel Sci Technol, 2017, 82, 1 (2017).

14. N. Liu, K. Huo, M. T. McDowell, J. Zhao, and Y. Cui, Sci. Rep., 3, 1919 (2013).

15. R. Yi, F. Dai, M. L. Gordin, S. Chen, and D. Wang, Adv. Energy Mater, 3, 295 (2013)

16. H. Föll, M. Christophersen, J. Carstensen, and G. Hasse, Mater. Sci. Eng. R., 39, 93 (2002).

17. G. X. Zhang, in Modern Aspects of Electrochemistry, C. Vayenas and M. E. Gamboa-Adelco, Springer, Boston, USA, (2006).

18. L. T. Canham, in Handbook of porous silicon, L. T. Canham, Springer International Publishing, Switzerland (2014).

19. V. Lehman and H. Föll, J. Electrochem. Soc., 137, 653 (1990).

20. V. Lehman and S. Rönnebeck, J. Electrochem. Soc., 146, 2968 (1999).

21. V. Lehman, R. Stengl, and A. Luigart, Mater. Sci, Eng. B, 69-70, 11 (2000)

22. S. Mariani, L. Pino, L. M. Strambini, L. Tedeschi, and G. Barillaro, ACS Sens., 1, 1471 (2016).

23. H. W. Lau, G. J. Parker, and R. Greef, Thin. Solid. Films, 276, 29 (1996).

24. A. V. Chernienko, E. V. Astrova, and Y. A. Zharova, Tech. Phys. Lett., 39, 990 (2013).

25. E. A. Ponomarev and C. Lévy-Clément, J. Porous Mat., 7, 51 (2000).

26. S. Haldar, A. De. S. Chakraborty, S. Ghosh, and U. Ghanta, Procedia Mater. Sci., 5, 764 (2014).

27. W. S. Rasband, U. S. National Institutes of Health, Bethesda, Maryland, USA, 1997.

28. D. B. Mawhinney, J. A. Glass, and J. T. Yates, J. Phys. Chem. B, 101, 1202 (1997). 